
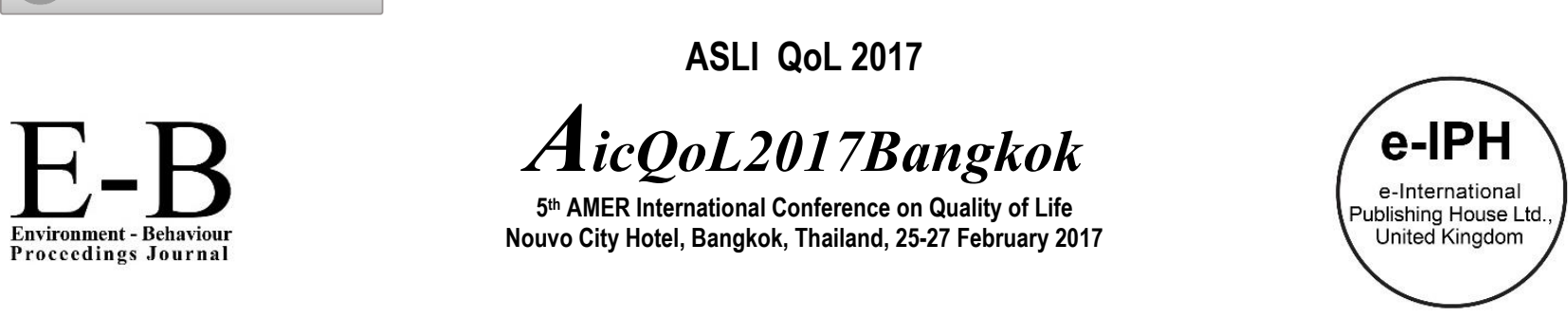

\title{
Preliminary Survey of Safety and Health Cost Framework for Urban Rail Infrastructure Project in Malaysia
}

\author{
Izatul Farrita Mohd Kamar ${ }^{1 *}$, Asmalia Che Ahmad ${ }^{2}$, Mohmad Mohd Derus ${ }^{3}$, \\ Nik Nur Khairunnisa Nik Mohd Ainul Azman 4 \\ ${ }^{1}$ Centre of Postgraduate Studies, ${ }^{2,3,4}$ Department of Quantity Surveying, \\ Faculty of Architecture, Planning and Surveying, Universiti Teknologi MARA, Seri Iskandar Campus, Seri Iskandar, 32610, Perak, Malaysia
}

\begin{abstract}
This paper presents the findings of a preliminary survey, which is consist of three criteria as the main focus, namely the identification of critical phases for safety cost allocation, issues, and importance of safety and health cost allocation and potential respondent for this research. Semistructured interviews were conducted with seven (7) construction stakeholders who are involved in urban rail infrastructure project. The transcription and interpretation from the interview findings were carried out using Atlas.ti@ qualitative software. The respondent views are needed to obtain safety items and related issues in developing this framework mainly for estimating the safety cost allocation.
\end{abstract}

Keywords: Safety and Health Cost; Cost Framework; Urban Rail; Infrastructure Project.

ISSN: 2398-42870 2017. The Authors. Published for AMER ABRA by e-International Publishing House, Ltd., UK. This is an open access article under the CC BYNC-ND license (http://creativecommons.org/licenses/by-nc-nd/4.0/). Peer-review under responsibility of AMER (Association of Malaysian Environment-Behaviour Researchers) ABRA (Association of Behavioural Researchers on Asians) and cE-Bs (Centre for Environment-Behaviour Studies), Faculty of Architecture, Planning \& Surveying, Universiti Teknologi MARA, Malaysia.

\subsection{Introduction}

The Construction industry is an essential sector of the economy in Malaysia. The state of the construction industry in a country is symptomatic of its national economy. In other words, the fate of any national economy cannot be separated from the construction industry. Construction is a complex activity where various stakeholders are working under constant challenges from the demands of the job, and many of the activities are exposed to different risk and hazard. Mehta and Agnew (2010) argued that each job has diverse safety and risk factors. Ehsan et al. (2010) concurred that all project activities are complex and time-consuming which include planning, executing and maintaining involved in the process. The situation has become more complex with the existing of many external factors such as organisational structure, communication, clear instructions, safety culture, codes and standards, training, leadership, and responsibility. These factors have been suggested to have an influence on the general safety issue at the workplace.

López-Alonso et al. (2013), reported that the rate of accidents at the construction workplace is higher compared to other sectors. It encounters very complex practices, which includes the clients or the project owners, the contractors, which can be divided further into main contractors, subcontractors and specialist contractors, the designers, which includes all of the project consultants and the suppliers. The safety issue is a very sensitive matter since it deals with human life. Nevertheless, financial aspect has been neglected as everybody wants everything to be safe but nobody wants to pay a single cent for it. Work injuries create significant economic and humanitarian consequences to our society.

According to SOCSO (2001), the number of compensation recipient has increased $36 \%$, i.e 182,763 person in 1995 to 247,790 people in 2003. In 2003 alone SOCSO had paid about RM 754 million, a staggering of 161\% had been increased from RM 289 million in 1995, as compensation for the industrial accidents. In the year 2004, it had been estimated that the amount of compensation had reached over RM 800 million which is payable to over 260,000 recipients (Fong, 2004). SOCSO in 2012 reported that in 2011, a total

\footnotetext{
${ }^{*}$ Corresponding author. Tel.: +60-0192773374

E-mail address: izatu739@perak.uitm.edu.my
}

ISSN: 2398-4287@ 2017. The Authors. Published for AMER ABRA by e-International Publishing House, Ltd., UK. This is an open access article under the CC BYNC-ND license (http://creativecommons.org/licenses/by-nc-nd/4.0/). Peer-review under responsibility of AMER (Association of Malaysian Environment-Behaviour Researchers), ABRA (Association of Behavioural Researchers on Asians) and CE-Bs (Centre for Environment-Behaviour Studies), Faculty of Architecture, Planning \& Surveying, Universiti Teknologi MARA, Malaysia.

DOI: http://dx.doi.org/10.21834/e-bpj.v2i5.712 
of RM 1.7 billion were paid out to 378,377 beneficiaries of Social Security Organisation (SOCSO) which included to the construction workers.

Previous studies had shown that after the occurrence of an accident, there are various losses had to be incurred by parties involved (Davies and Teasedale, 1994; Jallon et al., 2011; Goetsch, 2013; N. Abd Rahman, 2014; Pellicer et al., 2014; Feng et al., 2015; Ibrahim et al., 2013). These losses may include costs to victims and their families as well as to employers and society. In addition, it also affects construction company's profit and loss statement by corresponding damages to productivity, property, equipment and morale. Moreover, the occurrence of an accident may increase cost and loss of contractors' reputation and other losses too as a result of delays in the completion of a project. The costs associated with these accidents are both human (not directly measurable) and financial either to companies or to society as a whole (sick leave, medical treatment, etc.).

Based on the Health and Safety Association HSA Report (2006), there is the wide range of negative costs and effects resulted from accidents. In terms of financial costs to employers, the amounts were varied greatly from 0 dollars to over 4.1 million dollars. The average cost of the twelve middle-range accidents was approximately 57,000 dollars. The costs were found in almost all cases underestimates, as productivity employers did not record losses. Employers' costs from the accidents include salary, costs for replacement staff or overtime payments, production and productivity losses, retraining costs, personal injury claim compensation, repair bills, medical and travel expenses as well as increased supervision. Salary costs were the largest cost category, being nearly half $(45 \%)$ of the total losses.

In summary, accidents are expensive to many parties, and substantial savings can be made by preventing them. Hence, preventing workplace accidents should make a good economic sense for contractors. It is also necessary to ensure that safe working practice is being observed (Marhani et al., 2014) Thus, this paper aims to identify critical phases for safety cost allocation throughout the life cycle of the construction project, issues, and importance of safety and health cost allocation and potential respondent for this research. Respondents' views had been obtained in developing this framework in order to estimate the cost allocation that should be provided by the client. Through the specific costs identified, it would motivate the cost minimisation for firms to increase investment in accident prevention as well as to improve the safety performance of construction projects.

\subsection{Issues and problems of safety and health costs allocation for urban rail infrastructure project}

Investment in infrastructure requires a significant amount of public funds. In the case of intercity transport, most of the corridors are now in operation and investments in large projects, such as high-speed rail (HSR), can be viewed as a means to reduce the cost of traveling (time and cost savings, reliability, comfort and externalities) with respect to the situation prevailing without project (De Rus, 2011).

In Malaysia, the construction of high-speed rail or also known as rail infrastructure project was started operational since 2002 for Light Rapid Transport (LRT) and Kuala Lumpur (KL) Monorail services. This construction has been managed by Syarikat Prasarana Negara Berhad, who focuses on major public transport infrastructure projects in Malaysia. This project is expanding all over the time to enhance and integrate the urban public transportation services; one of the National Key Result Areas, which is a priority under the Government Transformation Program. Through the rapid construction of this project, we can hear the serious injuries and damage to properties at recent of this project sites have occurred every year. This issue has also been concerned by the Institution of Engineers Malaysia (IEM) through it press statement on 1st July 2014. In view of these incidents, IEM considers that it is important to highlight the need to strictly observe strict safety procedures in construction work especially in on-going construction sites located adjacent to public access areas.

Numerous studies had attempted to explain the various losses that could be sustained by companies after the occurrence of an accident. Many researchers found that these losses may affect the implication of costs, such as delay in project implementation, impaired company image or market loss. Moreover, Feng et al. (2015) in his discussion indicated that other cost losses to victims and their families, employers, and society may be involved. Simultaneously, accidents and the corresponding damage due to productivity, property, equipment and morale can have detrimental effects on a construction company's profit and loss statement. All these losses should be borne by the contractor during the construction.

However, according to Feng et al. (2014) the quantification, evaluation, and identification of many of the losses incurred in an accident are difficult as they are "hidden". These "hidden" costs may be significant, and some may be particularly prominent in the construction industry. Jallon et al. (2011a) supported the same view about the "hidden" costs as being difficult to isolate, identify, evaluate and therefore quantify. These hidden costs are often hard to calculate due to several factors, such as limited safety elements in the preliminary item. In general, there are limited provisions for safety elements in the bills of quantities. Malaysia Standard Method of Measurement of Building Works (SMM 2) (2000) Clause B.12, stated that the safety, health, and welfare of the workplace will be deemed included in the pricing of the preliminary item. The provision allocated in this clause is very ambiguous and does not include specific details.

Another factor is difficulty in applying the existing models. It is not easy to apply the models used to analyse and calculate the costs of prevention in the construction industry. This is because, firstly, they are based on studies carried out in the manufacturing sector, and secondly, the use of the traditional models which are applied for analysing these costs is limited to identifying and classifying them. López-Alonso et al. (2013) believed these models should be tailored to each company according to its own circumstances. There are a few economic safety cost models from different countries such as Singapore, United Kingdom, Australia and Malaysia. However, the limitation of those economic models does not include the costs incurred by employers for compliance with work health and safety regulations and safety cost prevention activities. 
According to Jallon et al. (2011b) for Occupational Health \& Safety (OHS) stakeholders on the ground, there is the issue of the insufficiency of mathematical models and complex calculations which are needed to prove the economic benefits of the safety investment. Reliable data on compensation costs like insurance are easy to obtain, however not much information can be found related to indirect costs such as absence, productivity loss, supervision, etc. in the workplace. Thus, managers use only part of the cost evaluation method proposed by researchers, abandoning some indirect cost components because of the difficulty in finding them, the complexity in quantifying them, or the marginal nature of their impact. It is often hard to calculate these hidden costs since the issues involved with trying to quantify the specific degree of their economic consequences; another problem is the way these costs are usually tracked in the traditional practices of accounting.

Moreover, the minimal research on safety and health items for rail infrastructure project was another factor in evaluating the safety costs allocation. A number of studied on safety performance, safety culture, safety leadership and safety compliance in the construction industry had been carried out. Other researches had been conducted to study the safety cost model in the manufacturing sector while some researchers had carried out studies related to accident costs (direct and indirect costs) which focused more on the construction stage of a project. In contrast, there are limited studies which had been conducted to investigate the safety costs allocation, which involved the pre-construction and the construction stage particularly for rail infrastructure projects. Therefore, both the direct and indirect costs of accidents need to be examined to reflect the true costs of accidents to an employer. Due to limited studies covered on the safety cost for the construction of rail infrastructure projects, this study attempts to fill the gaps. Findings from the preliminary surveys will establish the issues, problems and importance of safety and health allocation for urban rail infrastructure projects in Malaysia. In addition, the potential respondents also will also be identified for the main study data collection of this research.

\section{Safety and health costs typologies}

The study of costs of an accident was pioneered by Heinrich (1931) more than 80 years ago. There are many different terms for safety and health costs were identified by other researchers. Since then, (López-Alonso et al. 2013)) clarified the cost related to safety and health in the workplace into three groups:

\section{1) Safety Cost}

Safety cost is distinguished between prevention costs and those of evaluation and monitoring. Prevention costs are those incurred in order to comply with legal requirements with respect to accident prevention, to implement measures to prevent accidents during construction work and to improve health and safety conditions in all areas of the work performed. In relation to evaluation and monitoring costs, these are derived from the actions taken by the company for appropriate testing and maintenance of the health and safety measures adopted, regarding every facet of the work in question, with the aim of reducing or minimizing the risk of accident or occupational disease.

\section{2) Non-Safety Cost}

Non-safety cost is produced by not ensuring health and safety at work, i.e., the costs a company must meet following accidents, as well as those that may arise from breaches of safety regulations. Non-safety cost can be categorised into tangible and intangible costs of accidents. Tangible costs of accidents reflect the costs associated with the occurrence of an accident at work, which can be estimated or calculated using traditional cost accounting methods, while intangible costs of accidents, are the costs which are not measurable in economic terms or for which there are no performance indices to measure their impact on the organisation, such as impaired company image, low worker morale, labour disputes or loss of market (Gosselin, 2004).

\section{3) Other Extraordinary Costs}

This cost includes all losses provoked by events that cannot be prevented by the technical or human resources available to construction works, or which are totally unavoidable, such as natural disasters. This cost category includes all the items that are beyond the scope and control of the management, and thus are classified as uncontrollable costs, which cannot be incorporated into a structured model designed to control costs regarding safety in the workplace.

KLIACS JKKP (2013) stated that safety costs or direct costs are those costs that are accrued directly from the accident. The direct costs of accidents tend to be those associated with the treatment of the injury and any compensation offered to workers as a consequence of being injured. The direct accident costs are typically the costs covered by SOCSO and insurance company. Direct costs are usually insurable and they are quite easy to calculate.

While the non-safety costs or indirect costs are the consequences of an accident that can be costly. They are more difficult to calculate and tend not to be insured. There are a few different definitions of indirect cost (uninsured cost), but in general, they are regarded as consisting of all the cost items that are not covered by the worker's compensation insurance. The uninsured costs of accidents comprise several components such as loss due to injured person/worker, loss due to the inefficiency of the worker who had just recovered from injury upon resuming work, loss due to medical expenses, loss due to fines and legal expenses, loss of productivity of other employees, loss due to damaged equipment or plant, loss due to damaged material or finished work and loss due to idle machinery or equipment. The components of indirect costs were originated from studies that focused on accident costs in various industries (e.g., construction, furniture, forestry, chemistry, cleaning service, financial service, and manufacturing).

However, there are limited studies on extraordinary cost addressed for the construction industry (Lopez et al. 2013). Although this cost rarely happens, but the allocation for this item is significant as it may contribute to vast financial losses to contractors. The 
variables related to the direct cost will be used for preventive costs in safety management and these costs will be insured by the company, whereas the indirect costs will be taken into account during the construction phase. Although many studies have shown that the indirect accident costs are significant, there is no generally accepted ratio between direct and indirect costs of accidents.

\subsection{Research Methodology}

A qualitative approach is used to identify the critical phases for safety cost allocation, issues, and importance of safety and health cost allocation and potential respondent for the main study data collection of this research. Semi-structured interviews were conducted with seven (7) construction stakeholders who are involved in urban rail infrastructure project. Inputs from them are needed to establish the importance of this research. The transcription and interpretation from the interview findings are carried out using Atlas.tic qualitative software. To ease the semi-structured interview process, the questions were prepared in an interview form. The initial process for the semi-structured interview is short-listing the potential participants based on the stipulated respondents' criteria. Screening forms were distributed earlier via email to the potential participants. This is to obtain their demographic details that include their designation, academic background, years of working experience and current responsibility/duty.

\subsection{Analysis and Findings: Preliminary survey}

This research describes the qualitative approach namely the semi-structured interview. The analysis is based on the quotations from the participants, which had been labeled as $P=$ Participant and $Q=Q$ uotation (P: $Q$ ). The interview form consists of a cover page and four sections:

(1) demographic background of the interviewee(s);

(2) the critical phases for safety cost allocation;

(3) the issues and the importance of safety and health cost allocation; and

(4) the potential respondent for the main study data collection.

\subsection{Demographic background}

General demographic data were compiled from the participants, which include their working experience and their position at the respective organization. Table I presents the summary of the participants' demographic background. A majority of the participants, who represent 86 percent out of total participants, were male. Different types of participant's position were representing the different view of issues and importance of safety allocation. In terms of participant's working experience, it was found that majority of them, who represent $57 \%$ of the participants, had been working within the range of 3 to 5 years. Albeit a relatively small percentage, experienced professionals (working experience of more than 15 years) were also represented in the sample. In terms of current types of the project involved, the majority of the participants $(71 \%)$ are found to be actively involved in rail infrastructure projects, which are MRT project, LRT 2 and LRT 3 projects in Malaysia. The expert's view in terms of the issues and importance of safety cost allocation is more reliable since the majority of participants have experience in the rail infrastructure projects.

Table 1. Demographic background of interview participants

\begin{tabular}{|c|c|c|c|}
\hline Items & Sub-items & $\begin{array}{l}\text { Frequency } \\
\text { (N) }\end{array}$ & Percentage (\%) \\
\hline \multirow[t]{2}{*}{ Gender } & Male & 6 & 86 \\
\hline & Female & 1 & 14 \\
\hline \multirow[t]{5}{*}{ Respondent's Position } & Project Director & 1 & 14 \\
\hline & Safety Officer & 2 & 29 \\
\hline & Traffic Safety & 1 & 14 \\
\hline & Senior Safety Manager & 1 & 14 \\
\hline & Quantity Surveyor & 2 & 29 \\
\hline \multirow[t]{3}{*}{ Working Experience } & $3-5$ years & 4 & 57 \\
\hline & $10-14$ years & 1 & 14 \\
\hline & 15 years and above & 2 & 29 \\
\hline \multirow[t]{4}{*}{ Current Types of Project Involved } & Infrastructure project (infra pipe jacking) & 2 & 29 \\
\hline & Infrastructure project (rail infrastructure-MRT) & 1 & 14 \\
\hline & Infrastructure project (rail infrastructure-LRT 2) & 3 & 43 \\
\hline & Infrastructure project (rail infrastructure-LRT 3) & 1 & 14 \\
\hline \multirow[t]{2}{*}{ Company } & Client - Project Delivery Partner & 1 & 14 \\
\hline & Contractor & 6 & 86 \\
\hline
\end{tabular}

\subsection{The critical phases for safety cost allocation}

Table 2 shows the construction phases, i.e. pre-construction, construction and post-construction phase throughout lifecycle in the construction project. Since the majority of participants had experience in the previous development in rail infrastructure project, they were required to answer which construction was critical for safety cost allocation. The result shows that majority of participants choose the construction phases as the most critical phases of the construction project, followed by the pre-construction and post- construction. 
Table 2. Construction phase throughout lifecycle in construction project

\begin{tabular}{lll}
\hline Construction Phase & Mean & Rank \\
\hline Pre-Construction & 2.00 & 2 \\
Construction & 1.29 & 1 \\
Post-Construction & 2.71 & 3 \\
\hline
\end{tabular}

Notes: 1 = Most critical; 2 = Critical; 3 = Low critical

\subsection{The issues and importance of safety and health cost allocation}

Basically, for the section of issues and importance of safety and health cost allocation, it has been divided into several issues which are:

- Provisions of safety items in the Bills of Quantities (BQ)/Lump Sum Contract

- Determination of safety and health cost (direct \& indirect costs) in construction project

- Traditional/existing safety cost model in construction project

Based on the network of relationship, as seen in Figure 1, it is revealed that the provisions of safety items are lump sum cost where it is stated in the preliminaries item in the contract document as per stated by Participant 1, in Quotation 4 (P1:Q4). This is supported by the rest of participants (P2:Q1, P3:Q4, P4:Q4, P5:Q4, P6:Q4, P7:Q4). It is also revealed that safety cost allocation provided in the BQ is not enough by Participant 1, Quotation $5(\mathrm{P} 1: \mathrm{Q} 5)$ and also verified by other participants in their quotations (P2:Q2, P3:Q5, P7:Q5). However, other participants said that the provisions of safety items in the $B Q$ are enough but excluding the cost incurred after the accident happened (P4:Q5, P5:Q5, P6:Q5). If the accident happened, the cost incurred will be reviewed back to look into the accident causes, whether it is from the design error or lack of safety itself (P4:Q6). In addition, Participant 7, Quotation 6 (P7:Q6) explained that the safety budget in the preliminaries item always have been reduced by the client is the common problem in Malaysia. Due to that issue, the contractor will comply and provide the safety and health items within the budget that had been reduced by the client (P7:Q7).

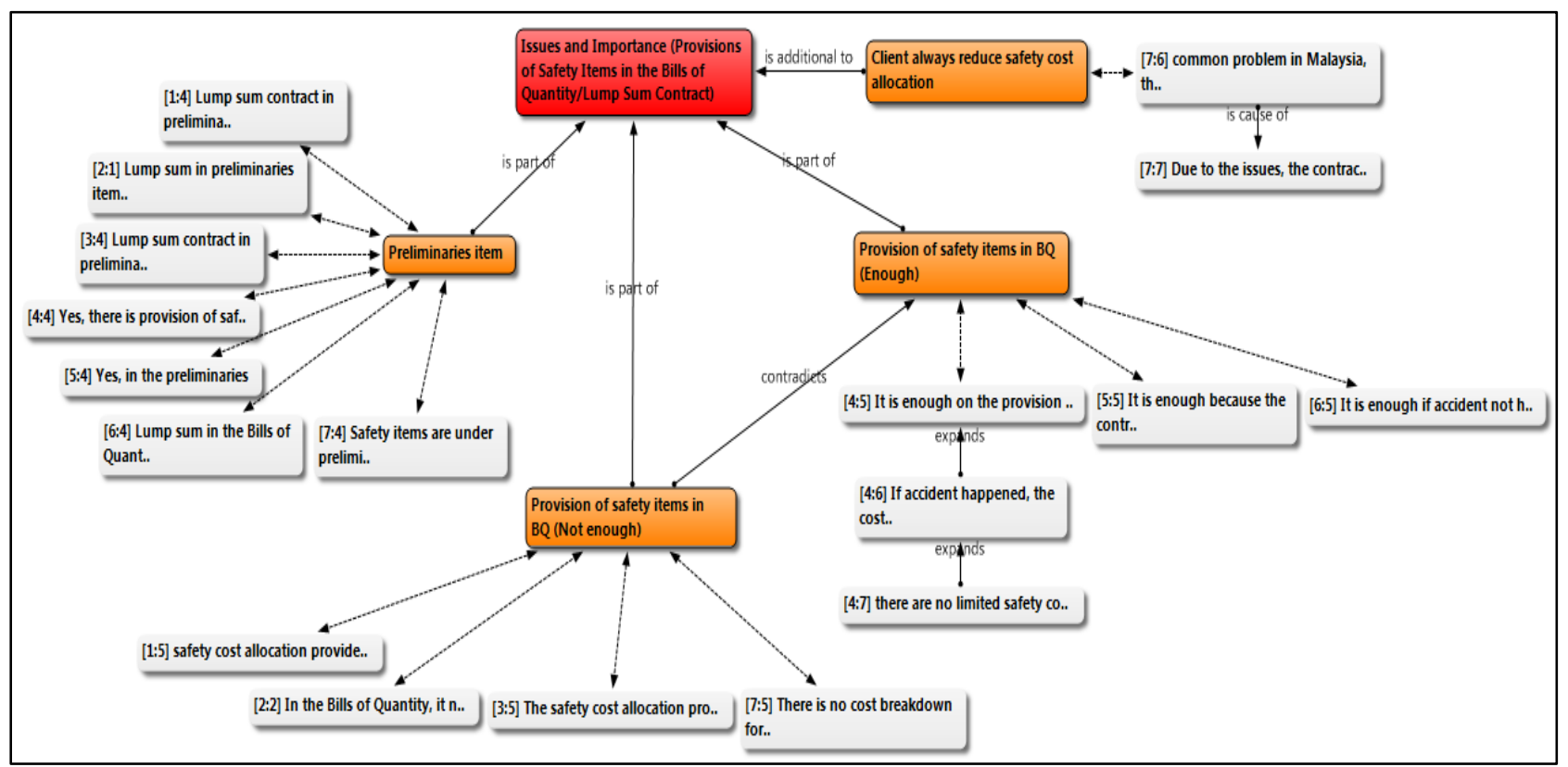

Fig. 1: Provision of Safety Items is the Bills of Quantity / Lump Sum Contract

For the determination of safety and health cost allocation, as seen in Figure 2, the participants revealed the direct costs are predictable costs, while indirect costs are the unpredictable costs that incurred the contractor. The participants explained the types of direct costs are such as insurance, personal protective equipment (PPE), medical costs, repair costs, safety equipment's (e.g: safety harness, flagman, signage, scaffolding), seminar or training costs and production costs when stop work order given by the authorities (P1:Q7, P2:Q6, P3:Q6, P4:Q8, P5:Q6, P6:Q6, P7:Q8). While types of indirect costs are replacement of workers, recruitment with the new workers, medical cost (uninsured by insurance), cost to send back the worker's body (foreign labour), clearing costs, investigation costs and the delay of production costs due to stop work order by authority (P1:Q8, P4:Q10, P5:Q8, P6:Q8, P7:Q10). Majority of participants did not calculate the direct and indirect costs (P2:Q7, P3:Q7, P5:Q7, P6:Q7, P7:Q9) due to they are more concentrate on the authorities' requirements in construction project and cost losses incurred from the accident are hidden and difficult to quantify (P1:Q10). Commonly, the costs were calculated by the accounting department with project director of the company (P1:Q9). Only Participant 4, Quotation 9 was calculated the direct and indirect costs (p4:q9). Based on his experience, the cost estimation is around $2.5 \%$ of the total project cost (P4:Q11). While for the indirect costs estimation is about 10\% from the total safety cost allocation, which 
is under contingencies item (P4:Q12). The Participant 6 \& 7 explained the other cost that always occurred for rail infrastructure project is extraordinary costs, which are the flood that effect to the house damage near the construction site and flat tire of public vehicles due to the road they used near the construction site (P6:Q7, P7:Q11).

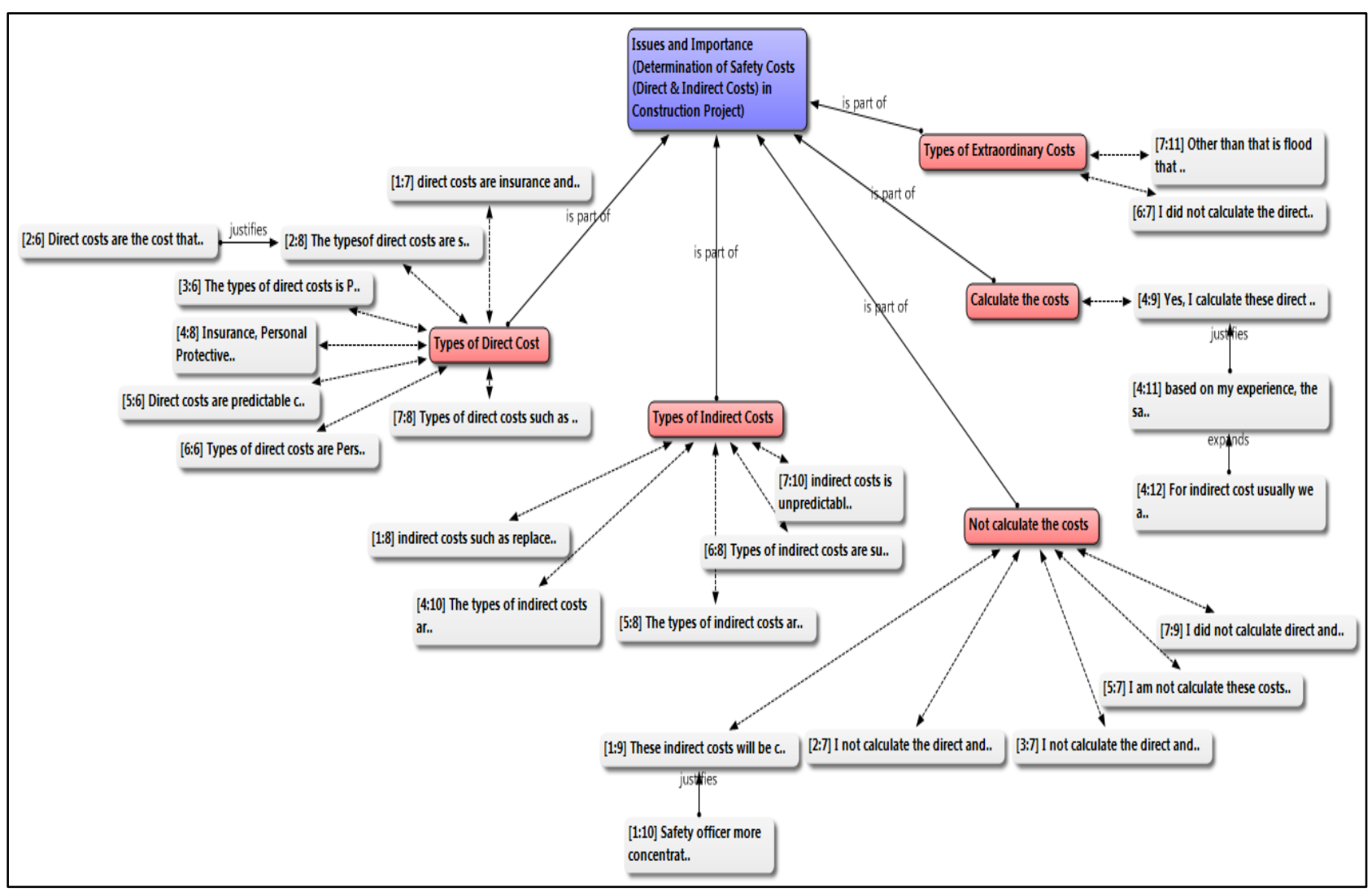

Fig. 2: Determination of Safety Costs (Direct and Indirect Costs) in Construction Project

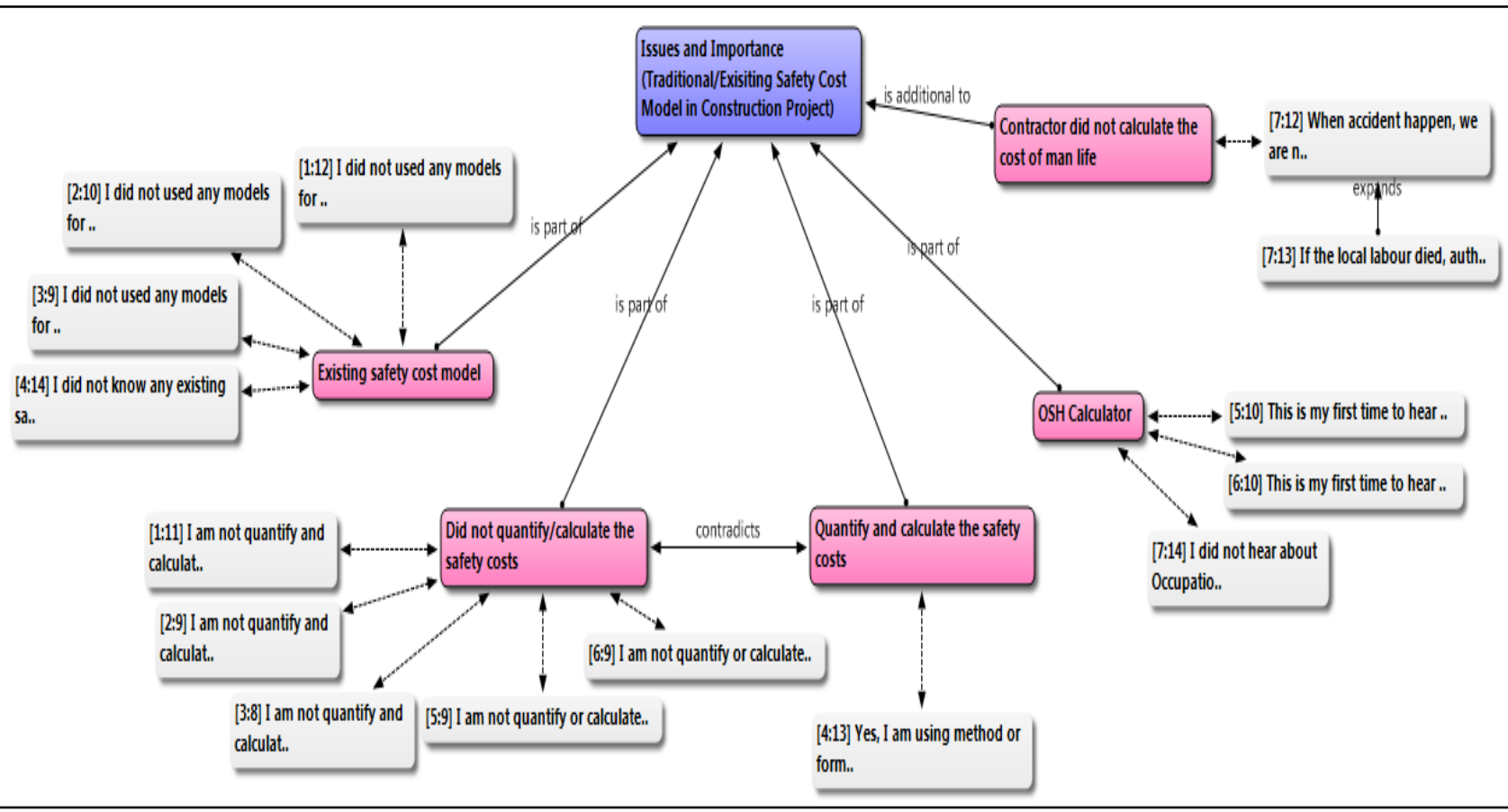

Fig. 3: Traditional / Existing Safety Cost Model in Construction Project 


\subsection{The potential respondent for the main study data collection}

The last issue for the safety cost allocation is traditional/existing safety cost model in a construction project. Majority of the participants did not use any safety cost model and for costing those safety elements (P1:Q12, P2:Q10, P3:Q9, P4:Q14) because they did not quantify or calculate the direct and indirect costs for the construction project (P1:Q11, P2:Q9, P3:Q8, P5:Q9, P6:Q9). However, Participant 4, Quotation 13 (P4:Q13) had calculated the safety and health costs items by using Microsoft Excel as safety estimation method. While other participants did not know about Occupational Safety and Health (OSH) Calculator provided by Department of Occupational Safety \& Health (DOSH), which is the first safety cost model in Malaysia (P5:Q10, P6:Q10, P7:Q14). In contrast, Participant 7 in his Quotation 12 (P7:Q12) revealed that when the accident happened, the contractor did not calculate the cost because if for man life, people are not considered and calculate the cost. They go to the insurance claim (P7:Q13).

Based on Table 3 shows that the results of potential respondents for the main study data collection. The most suitable potential respondents were contractor followed by the safety officer and lastly client. However, the specific position in contractor's company is a Project Director, who is the most relevant person to answer the questionnaire survey.

Table 3. Potential respondent for the main study data collection

\begin{tabular}{lll}
\hline Potential Respondents & Mean & Rank \\
\hline Government Sector & 3.71 & 4 \\
Client & 3.43 & 3 \\
Consultant & 3.86 & 5 \\
Contractor & 2.00 & 1 \\
Safety Officer & 2.57 & 2 \\
PERKESO & 5.57 & 6 \\
Insurance Company & 6.86 & 7 \\
\hline
\end{tabular}

\subsection{Discussion}

The findings show that most critical phase for safety cost allocation is during the construction phase of the construction project. This participant's view is also supported by Guo et al. (2013) stated in large-scale construction projects, due to the involvement of many workers, many large and heavy plants, a lot of materials, complex construction operation, multi-interface, and complex management activities, the accident rate is higher than that of common construction projects. Therefore, it is needed for safety cost allocation during this phase. Complete itemised safety cost budget is necessary to give the contractor and other construction industry players a reasonably accurate idea to help them realise on the price incurred if the accident occurs.

The findings are also in agreement with the studies of issues and importance of safety and health cost allocation for the construction project. The results from the participants show it is parallel with previous studies by Feng et al. (2014), Jallon et al. (2011b) and Oxenburgh and Marlow (2005) which explained the problems of safety cost allocation is hidden and difficult to quantify, evaluate and identify by the contractor. These hidden costs are often difficult to calculate due to several factors, such as limited safety elements in the preliminary item as shown from the interview findings. This is supported in Malaysia Standard Method of Measurement of Building Works (SMM 2) (2000) Clause B.12, only stated that the safety, health, and welfare of the workplace will be deemed included in the pricing of the preliminary item. The provision allocated in this clause is very ambiguous and does not include specific details. Due to difficulties, the majority of the participants did not know about the existing safety cost models including OSH Calculator, which is prepared by the DOSH, Malaysia. Moreover, they did not use any tool in calculating safety cost allocation for the construction project.

Besides that, another participant revealed that when the accident happened, the contractor did not calculate the cost because it relates to the human life. They go directly to the insurance claim. This problem also has been highlighted by the KLIA (JKKP) (2008), that another common downside with our project practice is the tendency for clients, consultants, and contractors to ignore the cost of the accident without realising the greatness of it impacts to the industry and the country. This is particularly true for all of the government projects because of the government policies that require all projects to be insured. Too often, because of that, the awareness of accident cost especially the payment cost are absent because the contractors, clients, and the consultants leave the matters to the insurance company.

For the potential respondents of the main study data collection, it is revealed that the most suitable potential respondent was contractor followed by the safety officer and lastly client. It was supported by Teo \& Feng (2011), who described that the workplace accidents in the construction industry may also cause considerable financial losses for individual contractors. Therefore,the contractor is the related person with the safety cost allocation followed by the safety officer and client, who also involved for the safety cost budget in the construction project.

\subsection{Conclusion}

The research presented in this paper is initially and part of an ongoing $\mathrm{PhD}$ research at the Faculty of Architecture, Planning and Surveying, UiTM. This paper presents the findings of a preliminary survey, which is consist of the identification of critical phases for safety cost allocation, issues, and the importance of safety and health cost allocation and potential respondent for this research. This paper is an initial study with the hope that the finding will lead its way to the development of framework mainly for estimating the safety cost allocation. These would assist to determine the actual cost of workplace accidents in order to make better decision-making on 
safety and health allowance during pre-contract stages. This framework will later encourage the clients as well as the contractors to ensure safety budget are available for the projects to complete securely and successfully. The researcher will prolong this research with other method.

\section{Acknowledgements}

The authors gratefully acknowledge the Centre of Postgraduate Studies, Universiti Teknologi MARA, Seri Iskandar Campus, Seri Iskandar to support this research study. The research study described in this paper is also supported by Fundamental Research Grant Scheme (FRGS) under the Malaysian Ministry of Higher Education (MOHE). Project code: FRGS/1/2016/SSI11/UITM/03/1. Special gratitude is also given to those industrial practitioners for their kind cooperation and generous contributions to the development of this research.

\section{References}

Davies, N., V., \& Teasedale, P. (1994). The Costs to the British Economic of Work Accidents and Work-Related III-Health. Health and safety Executive, HMSO, London. De Rus, G. (2011). The BCA of HSR: Should the Government Invest in High Speed Rail Infrastructure? Journal of Benefit-Cost Analysis, 2(1), Article 2.

Ehsan, N., Mirza, E., Alam, M., \& Ishaque, A. (2010). Risk management in construction industry. Computer Science and Information Technology (ICCSIT), 2010 3rd IEEE International Conference on, 9, 16-21.

Feng, Y., Teo, E., A., L., Ling, F., Y., Y., \& Low, S., P. (2014). Exploring the interactive effects of safety investments, safety culture and project hazard on safety performance: An empirical analysis. International Journal of Project Management, 32(6), 932-943.

Feng, Y., Zhang, S., \& Wu, P. (2015). Factors influencing workplace accident costs of building projects. Safety Science.

Fong Chan Onn - Minister Of Human Resources. (2004). Speech in Majlis Penyampaian Faedah PERKESO Tampin, Negeri Sembilan, [online] Available: http://www.mohr.gov.my.

Goetsch, D., L., 2013. Construction Safety and Health, second ed. Pearson Education, Inc., New Jersey, USA.

Gosselin, M., 2004. Analyse des avantages et des Couts de la Sante et de la Securite au Travail en Enterprise: Development de l'outil D'Analyse. Rapport de, Recherche R-375.

Guo, H., L., Li, H., \& Li, V. (2013). VP-based safety management in large-scale construction projects: A conceptual framework. Automation in Construction, $34,16-24$.

Heinrich, H., W., 1931. Industrial Accident Prevention.McGraw-Hill, New York.

Report Hsa, H., A., S., A. (2006). Workplace Safety and Health Management, 54.

Ibrahim, I., I., Noor, S., M., Nasirun, N., \& Ahmad, Z. (n.d.). Favorable Working Environment in Promoting Safety at Workplace, 19-27.

Jallon, R., Imbeau, D., \& De Marcellis-Warin, N. (2011a). A process mapping model for calculating indirect costs of workplace accidents. Journal of Safety Research, 42(5), 333-344.

Jallon, R., Imbeau, D., \& De Marcellis-Warin, N. (2011b). Development of an indirect-cost calculation model suitable for workplace use. Journal of Safety Research, 42(3), 149-164.

KLIACS_JKKP .(2013). Kajian Mengenai Kos Kemalangan Di Tempat Kerja Bagi Sektor Pembinaan, 1-77.

López-Alonso, M., Ibarrondo-Dávila, M., P., Rubio-Gámez, M., C., \& Munoz, T., G. (2013). The impact of health and safety investment on construction company costs. Safety Science, 60, 151-159.

Marhani, M., A., Adnan, H., \& Ismail, F. (n.d.). OHSAS 18001 : Sustainable construction, 63-73.

Mehta, R., K., \& Agnew, M., J. (2010). Analysis of individual and occupational risk factors on task performance and biomechanical demands for a simulated drilling task. International Journal of Industrial Ergonomics, 40(5), 584-591.

N. Abd Rahman, Z., M., J. (2014). InCIEC 2014 International Civil and Infrastructure Engineering Conference, Kota Kinabalu, Sabah, Malaysia.

Oxenburgh, M., \& Marlow, P. (2005). The productivity assessment tool: computer-based cost benefit analysis model for the economic assessment of occupational health and safety interventions in the workplace. Journal of Safety Research, 36(3), 209-214.

Pellicer, E., Carvajal, G., I., Rubio, M., C., \& Catal, J. (2014). A method to estimate occupational health and safety costs in construction projects. KSCE Journal of Civil Engineering, 18(7), 1955-1965.

SOCSO .(2001). Statistik Kemalangan Industri, [online] Available: http://www.perkeso.gov.my/en/report/annual-reports.html.

Teo, E., A., L., \& Feng, Y. (2011). The indirect effect of safety investment on safety performance for building projects. Architectural Science Review, 54(1), 65-80. 